\title{
Factors Affecting Delivery Methods in Severe Preeclampsia Patients at Dr. RSUP. Mohammad Hoesin Palembang January 2018 - December 2019
}

\section{Hadrians Kesuma Putra ${ }^{*}$, Adnan Abadi ${ }^{2}$, Dinda Radeta ${ }^{3}$}

1,2Departemen Obstetri dan Ginekologi, Fakultas Kedokteran, Universitas Sriwijaya, Palembang, Indonesia

${ }^{3}$ Program Studi Pendidikan Dokter, Fakultas Kedokteran, Universitas Sriwijaya, Palembang,

\section{A R T I C L E I N F O Keywords: \\ Severe preeclampsia \\ Vaginal birth \\ Caesarean section delivery}

\section{*Corresponding author:}

Hadrians Kesuma Putra

E-mail address:

hadrianskesuma@fk.unsri.ac.id

All authors have reviewed and approved the final version of the manuscript.

https://doi.org/10.32539/bsm.v5i4.375

\begin{abstract}
A B S T R A C T
Background: Hypertension in pregnancy (HIP) is the second highest cause of maternal death in Indonesia. Termination of pregnancy in patients with HIP or preeclampsia is the most common treatment to save both the mother and the fetus. There are two methods of delivery that can be done, namely vaginal or abdominal termination (sectio caesaria). Due to the high incidence of severe preeclampsia in Indonesia and the various determinants in choosing a delivery method for severe preeclampsia, the aim of this study is to analyze what factors influenced it in Dr. Mohammad Hoesin Palembang Hospital. Methods: This type of study is an analytic observational study with a cross-sectional study design. A total of 210 samples were taken using the simple random sampling technique from the medical records of severe preeclampsia patients who gave birth at Dr. Mohammad Hoesin Palembang Hospital during January 2018 - December 2019 and was analyzed by univariate, bivariate and multivariate analysis with SPSS ver.26. Results: A total of $81(38.6 \%)$ PEB patients underwent vaginal delivery and $129(61.4 \%)$ underwent a caesarean section delivery. From the observations, 67 people $(57.3 \%)$ were aged $20-34$ years, 40 people $(78.4 \%)$ with a gestational age of 34-36 weeks, 92 people $(57.9 \%)$ multiparity, 104 people $(62.3 \%)$ without a history of hypertension, 86 people (53.4\%) without a history of SC, 98 people $(84.5 \%)$ with a bishop score 5, 116 people $(59.5 \%)$ without PJT, 122 people $(61 \%)$ without macrosomic fetuses, 108 people $(63.5 \%)$ without PROM, and 84 people $(75 \%)$ with complications undergoing cesarean delivery. The factors of gestational age $(\mathrm{p}$ value $=0.001)$, history of sectio caesaria ( $\mathrm{p}$ value = $0.000)$, bishop score ( $p$ value $=0.000)$, and complications or comorbidities $(p$ value $=0.000$ ) had a significant relationship to the method of delivery for patients with PEB with factors bishop score is the most influencing factor $(\mathrm{OR}=10.299)$. Conclusion: Therefore, gestational age, history of CS, bishop score, and complications or comorbidities are factors that influence the delivery method of PEB patients.
\end{abstract}

\section{Introduction}

Preeclampsia is a disorder in pregnancy characterized by an increase in blood pressure after the 20th week. Based on the severity, it is called preeclampsia if the increase in blood pressure is

$>140 / 90 \mathrm{mmHg}$ and it is called severe preeclampsia if the increase in blood pressure reaches $>160 / 110$ mmHg. Both are accompanied by proteinuria (>300 $\mathrm{mg} / 24$ hours) or the presence of one of the other symptoms such as thrombocytopenia, renal impairment, liver failure, or pulmonary edema 1,2 . The prevalence of preeclampsia in Indonesia is 128,273 /year or around 5.3\% and tends not to have a significant decline in the last two decades ${ }^{2}$.

HDK or preeclampsia accompanied by comorbidities in both the mother and fetus, in most cases can only be treated by termination of pregnancy. There are two methods of delivery that can be done, namely vaginal termination or per-abdominal (sectio caesaria) ${ }^{3}$. 
Determining the method of delivery for preeclampsia patients requires the right decision by looking at several factors so that it varies greatly. Nur Lathifah et al (2018) explained that in patients with severe preeclampsia, termination of pregnancy can be completed vaginally with previous induction of labor, while Hikmah (2014) explained that patients with severe preeclampsia are at risk for cesarean section 8 times. So this means that not all patients with severe preeclampsia

must be delivered by cesarean section (SC) (4).

The rate of caesarean section in patients with severe preeclampsia is estimated to be very high (ranging from $70 \%$ or more in preterm pregnancies), because many obstetricians prefer caesarean section in women with preeclampsia, even with reassuring fetal status ${ }^{5}$.

The results of the study by Jose Juvenal et al (2018) showed that of many variables such as maternal age, parity status, gestational age, history of hypertension, history of cesarean section, and degree of preeclampsia only gestational age had a threefold risk $(O R=3.1$; $\mathrm{p}<0.01$ ), history of hypertension with a risk of 2-3 times $(O R=2.5 ; \mathrm{p}<0.02)$, history of cesarean section with a risk of $1-2$ times $(O R=1.3 ; p<0.01)$, and the degree of preeclampsia with a risk of 3- 4 times $(O R=3.3 ; p<0.01)$ which had a significant relationship with the method of delivery performed6.

Due to the high incidence of preeclampsia in Indonesia and the determining factors in choosing the delivery method in severe preeclampsia, the researchers wanted to analyze what factors influence the delivery method at Dr. Mohammad Hoesin Palembang in patients with severe preeclampsia (PEB).

\section{Method}

This type of research is an analytical observational study with cross sectional study design. This study uses secondary data, namely records medical of patients with severe preeclampsia in the medical records section of Dr. RSUP. Mohammad Hoesin Palembang period January 2018 - December 2019. The research was carried out from August - October 2020 with the capture technique isample isimple random sampling as many as 210 samples were taken from a total population of 648 patients obtained PEB minimum sample size based on a formula that met the inclusion criteria and exclusion.

Inclusion criteria iwere pregnant women with severe preeclampsia who gave birth at Dr. Mohammad Hoesin with complete medical records containing all the variables studied (method of delivery, maternal age, gestational age, parity status, history of hypertension, history of CS, bishop score, stunted fetal growth (IUGR), macrosomia, premature rupture of membranes, and complications or other concomitant circumstances). Exclusion criteria were women with multiple pregnancies, severe preeclampsia patients who had illegible medical records or medical records with incomplete study variables.

From the medical record data, the data were analyzed univariately to see the frequency distribution of each variable, bivariate with chi-square to determine the relationship between each independent variable and the method of delivery as the dependent variable, and multivariate analysis using binary logistic regression test to see the variables which independent factors most influence the delivery method of PEB patients. In processing and analyzing the data in this study using the application SPSS Statistics ver.26.

\section{Results}

variables studied in this study included delivery method, maternal age, gestational age, parity status, history of hypertension, history of section caesarean (SC), bishop score, stunted fetal growth (PJT), macrosomia, premature rupture of membranes (PROM), and complications or other coexisting conditions in patients with severe preeclampsia (PEB) at Dr. Mohammad Hoesin Palembang January 2018 December 2019. The frequency distribution of each characteristic of PEB patients is presented in table 1. 


\begin{tabular}{|c|c|c|}
\hline Variable & Frequency & $\%$ \\
\hline \multicolumn{3}{|l|}{ Method of } \\
\hline Vaginal Delivery & 81 & 38.6 \\
\hline SectioCaesaria & 129 & 61.4 \\
\hline \multicolumn{3}{|l|}{ Age } \\
\hline 19 years & 7 & 3.3 \\
\hline $20-34$ years & 117 & 55.7 \\
\hline 35 years & 59 & 28.1 \\
\hline 40 years & 27 & 12.9 \\
\hline \multicolumn{3}{|l|}{ Gestational Age } \\
\hline$<34$ week & 34 & 16.2 \\
\hline $34-36$ weeks & 51 & 24.3 \\
\hline 37 weeks & 125 & 59.5 \\
\hline \multicolumn{3}{|l|}{ Parity status } \\
\hline Primiparity & 51 & 24.3 \\
\hline Multiparity & 159 & 75.7 \\
\hline \multicolumn{3}{|l|}{ History of hypertension } \\
\hline Yes & 43 & 20.5 \\
\hline None & 167 & 79.5 \\
\hline \multicolumn{3}{|c|}{ History of sectio caesaria } \\
\hline Ever & 49 & 23.3 \\
\hline Never & 161 & 76.7 \\
\hline \multicolumn{3}{|l|}{ Bishop Score } \\
\hline$\leq 5$ & 116 & 84.1 \\
\hline$>5$ & 22 & 15.9 \\
\hline \multicolumn{3}{|l|}{ PJT } \\
\hline Yes & 15 & 7.1 \\
\hline No & 195 & 92.9 \\
\hline \multicolumn{3}{|l|}{ Macrosomia } \\
\hline Yes & 10 & 4.8 \\
\hline No & 200 & 95.2 \\
\hline \multicolumn{3}{|c|}{ Premature rupture of membranes } \\
\hline Yes & 40 & 19 \\
\hline No & 170 & 81 \\
\hline \multicolumn{3}{|c|}{ Concomitant Complications } \\
\hline Yes & 112 & 53.3 \\
\hline None & 98 & 46.7 \\
\hline
\end{tabular}

Table 2 shows that from the age group with the highest frequency of PEB, from 117 mothers in the 20-34 year age group who experienced PEB, as many as 67 people $(57.3 \%)$ underwent cesarean delivery. . Based on the results of the test Chi Square, the $p$ value obtained is $0.522(p>0.05)$. This shows that there is an insignificant relationship between the age of the mother who experienced PEB and the method of delivery that was carried out.

From the results of the study, it was found that from a total of 125 people who entered the gestational age group 37 weeks with PEB, 64 people (51.2\%) underwent cesarean delivery. Based on the results of the test Chi Square, the p value obtained is 0.001 $(p>0.05)$. This shows that there is a significant relationship between the gestational age of the mother who experienced PEB and the method of

delivery that was carried out.

Table 2 shows that of the 159 mothers in the multiparity group who experienced PEB, 92 of them $(57.9 \%)$ underwent cesarean delivery. Based on the results of the Chi Square test, the $\mathrm{p}$ value obtained was 0.087 (p>0.05) (PR 1.254, 95\% CI). This shows that there is an insignificant relationship between the parity status of mothers who experience PEB and the method of delivery that is carried out.

From the results of the study, it was found that from 167 mothers who experienced PEB without a history of hypertension, 104 of them (62.3\%) underwent cesarean delivery. Based on the results of the Chi Square test, the p value obtained was 0.748 (p>0.05) (PR 0.934, 95\% CI). This indicates that there is an insignificant relationship between the history of 
hypertension in PEB mothers and the delivery method used.

Table 2 shows that of the 161 mothers who experienced PEB without a history of CS in previous pregnancies, as many as 86 people (53.4\%) of them underwent cesarean delivery. Based on the results of the Chi Square test, the p value obtained was 0.000 ( $p>0.05)$ (PR 1.643, 95\% CI). This shows that there is a significant relationship between the history of CS in women who experience PEB and the method of delivery that is carried out.

From the results of the study, it was found that from 116 mothers who experienced PEB with a bishop score 6, as many as 98 people (85.4\%) underwent caesarean section (SC). Based on the results of thetest Chi Square, the p value obtained is 0.000 $(p>0.05)$. This shows that there is a significant relationship between the bishop score of mothers who experience $\mathrm{PEB}$ and the method of delivery that is carried out.

From the results of the study, it was found that of the 195 mothers who experienced PEB without IUGR, as many as 116 people (58.8\%) underwent caesarean delivery. Based on the results of the test Chi Square, the $\mathrm{p}$ value obtained was 0.071 ( $\mathrm{p}>0.05$ ) (PR 1.289, 95\% CI). This indicates that there is an insignificant relationship between the condition of IUGR in pregnant women with PEB and the delivery method used.

From the results of the study, it was found that of the 200 mothers who experienced PEB without a macrosomic fetus, 122 people (61\%) underwent cesarean delivery. Based on the results of the Chi Square test, the $\mathrm{p}$ value obtained was $0.744(\mathrm{p}>0.05)$ (PR 1.148, 95\% CI). This indicates that there is a non- significant relationship between the condition of the macrosomic fetus in the pregnancy of the mother with PEB and the method of delivery performed.

From the results of the study, it was found that of 170 mothers who experienced PEB without PROM, as many as 108 people (63.5\%) underwent cesarean delivery. Based on the results of the Chi Square test, the $\mathrm{p}$ value obtained was 0.267 ( $\mathrm{p}>0.05)$ (PR 0.826, 95\% CI). This shows that there is an insignificant relationship between premature rupture of membranes (PROM) in mothers who experience PEB and the method of delivery that is carried out.

From the results of the study, it was found that of 112 mothers who experienced PEB with complications or other comorbidities, as many as 84 people $(75 \%)$ underwent caesarean section (SC). Based on the results of the test Chi Square, the $p$ value obtained was 0.000 ( $p>0.05)$ (PR 1.633, 95\% $\mathrm{CI})$. This shows that there is a significant relationship between complications or comorbidities in mothers who experience PEB with the method of delivery that is carried out.

Based on multivariate analysis, there are four variables that have significant $\mathrm{p}$-values so that they are considered to be factors that influence the choice of delivery method in PEB patients at Dr. Mohammad Hoesin Palembang Period January 2018 - December 2019 namely parity status, history of sectio caesaria (SC), bishop score, and complications or accompanying conditions.

The highest prevalence ratio (PR) is found in thevariable bishop score. So when viewed from the results of the prevalence ratio, the bishop score is the most dominant factor or the most influencing in determining the method of delivery undertaken by PEB patients. 
Table 2. The Relationship of the Method of Delivery in PEB Patients with Factors Affecting It

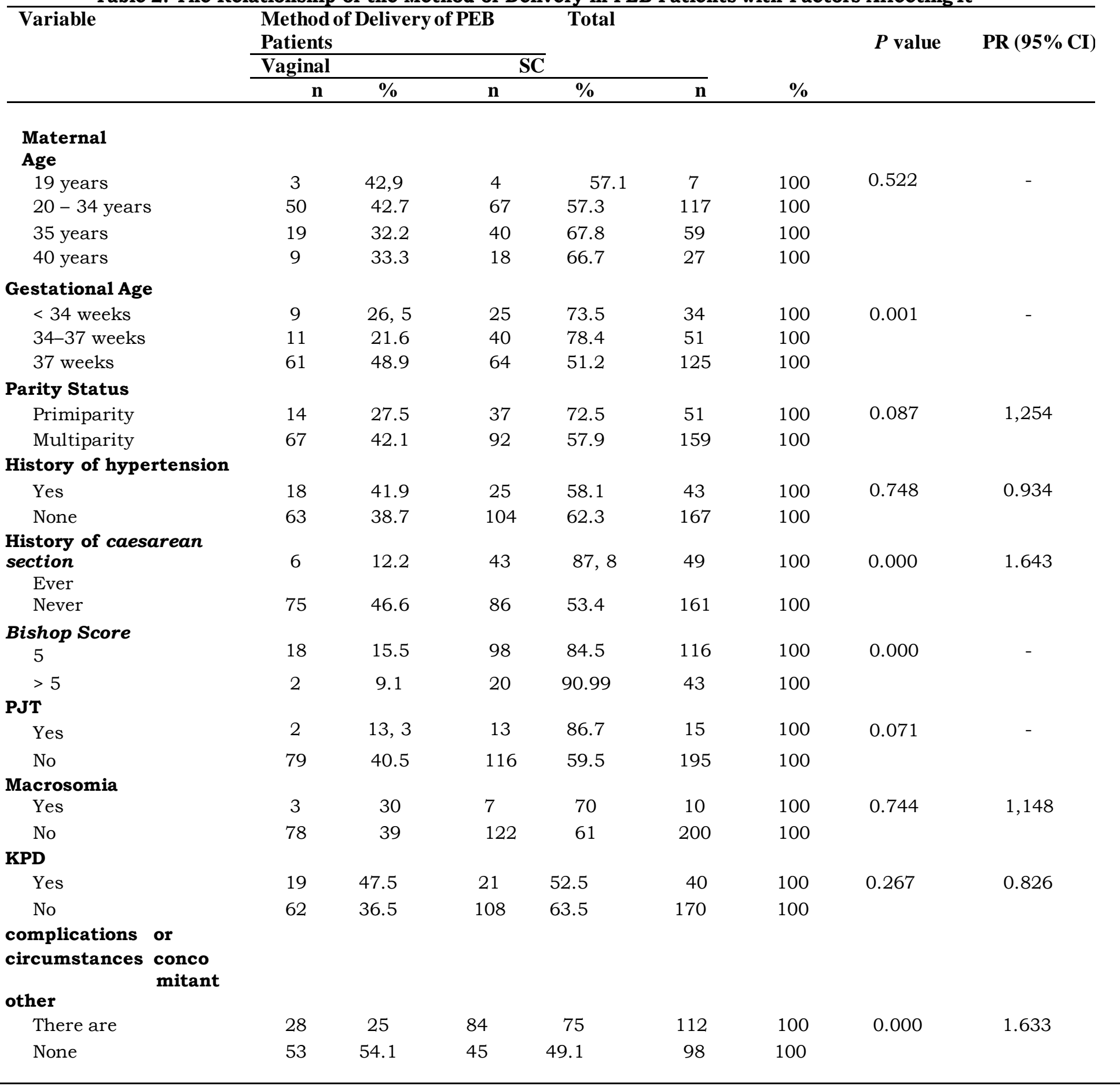


Table 3. Research Multivariate Analysis Final Model

\begin{tabular}{|c|c|c|c|c|}
\hline Variable Research & $\mathbf{B}$ & $\begin{array}{l}\text { Standard } \\
\text { error }\end{array}$ & $\mathbf{P}$ & Exp (B) $95 \% \mathrm{CI}$ \\
\hline $\begin{array}{l}\text { history SectioCaesaria } \\
1.9396 .951\end{array}$ & & 0.534 & 0.000 & $(\mathrm{SC})(2,441-19,794)$ \\
\hline Bishop Score & 10.299 & 0.365 & 0.000 & $2.332(5,035-21,068)$ \\
\hline $\begin{array}{l}\text { Complications or state } \\
\text { broadcaster }\end{array}$ & $\begin{array}{c}(1,578- \\
6,631)\end{array}$ & 0.362 & 0.001 & 1.1663 .211 \\
\hline Constants & $\begin{array}{c}- \\
1.593\end{array}$ & 0.323 & 0.000 & 0.203 \\
\hline
\end{tabular}

\section{Discussion}

Distribution Frequency preeclampsia Genesis Method Based Delivery

Delivery in patients with severe preeclampsia (PEB) may be performed either vaginally and sectio Caesaria (SC) (3). The results of this study showed that $61.4 \%$ of PEB patients delivered by cesarean section. This is in accordance with Hikmah's research (2014) which explains that patients with severe preeclampsia have an eightfold risk $(\mathrm{p}$ value $=0.000$; $\mathrm{OR}=8$ ) to terminate their pregnancy by CS when compared to patients who do not suffer from PEB. This is because besides preeclampsia is an absolute indication of cesarean delivery, severe preeclampsia with worsening conditions, cesarean delivery is also sometimes preceded by failed induction trials (7). Termination of pregnancy in PEB can also be accomplished vaginally by prior induction of labor (8). This theory can be seen from several samples in this study, it was found that 12 samples had cesarean delivery preceded by failed induction and 1 sample was a patient who underwent cesarean delivery due to failure of conservative therapy.

\section{Relationship between Maternal Age and Childbirth Methods for PEB Patients}

In the observation of medical record data of $\mathrm{PEB}$ patients based on maternal age, the lowest age with severe preeclampsia was adolescents aged 16 years and the highest age was 52 years. Based on the results of this study, the $\mathrm{p}$ value ( $\mathrm{p}$ value) was 0.522 ( $\mathrm{p}$ value $>0.05$ ) which indicated that the relationship between maternal age and delivery method in patients with severe preeclampsia at Dr. Mohammad Hoesin the period January 2018 - December 2019 is not significant. The results are consistent with studies dilakukan (Linhares 2014) that the maternal age effect is not significant to the determination of the method of delivery in preeclamptic patients with a $\mathrm{p}$ value is 0.1 ( $\mathrm{p}$ value $>0.05) .6$

However, no studies show that there is a significant relationship between the age of PEB mothers with the choice of delivery method. However, research by Renny and Yuven (2018) states that there is a significant relationship with a p value of $0.001(\mathrm{p}$ value $<0.05$ ) between maternal age and delivery method in pregnant patients with or without pregnancy abnormalities. Advanced maternal age (AMA) 40 years was also asses sed to have a significant relationship with $\mathrm{p}$ value $<0.001$ (OR $3.17 \mathrm{CI} 95 \%$ ) which means that it has a 3-fold risk of undergoing cesarean delivery 9. In this study, out of 129 PEB mothers underwent cesarean section, 15 of them underwent induction (accelerated labor with oxytocin) until the induction failed and had to undergo cesarean delivery. Ten out of fifteen people who experience induction failure are at risk age group $(\geq$ 35 years). This proves that age indirectly affects the method of delivery that is preceded by induction. Mothers who are nulliparous and elderly (>35 years) with a cervix that has not been fully dilated are more likely to have induction failure. Based on the theory, this is because in old age, the reproductive organs have experienced aging so that they are less responsive to induction actions to stimulate uterine contractions. 
Relationship between Gestational Age and

\section{Delivery Methods for PEB Patients}

Based on the NICE (National Institute for Health and Care Excellence) Guideline of Hypertension in Pregnancy, termination of severe preeclampsia can be carried out based on gestational age and other concomitant conditions. Basically, if there is already one of the emergency signs or complications of preeclampsia, then active management or termination of pregnancy must be done immediately, either vaginally or by cesarean section. To save the mother and fetus, cesarean section is a method of delivery that is performed because of the outcome, especially if the mother is not yet in labor, which is marked by a bishop score $<6$ or induction failure. However, not all cases of severe preeclampsia must be terminated by cesarean section 10 .

Indication for delivery in preeclampsia is done if there are signs of an emergency such as fetal distress, uncontrolled blood pressure, eclampsia, poor laboratory results, or poor maternal condition. Delivery performed for the above indications does not always require a cesarean section, but if the gestational age is $<32$ weeks, cesarean delivery is an option. This is related to the condition and maturity of the cervix (bishop score <6) which is prone to failure of the induction process 11 .

In theory, gestational age after more than 34 weeks, vaginal delivery can be considered (11). However, based on the results of this study, most PEB patients who gave birth by cesarean section were in the gestational age group 37 weeks as many as 64 people. This is because gestational age is not the only factor to consider doing CS. From the results of this observation, it was found that 12 out of 64 people who experienced induction failure had to undergo cesarean delivery and 6 of them were $>35$ years old where extreme age was one of the factors for induction failure due to aging reproductive organs so that they were less responsive to induction measures for stimulate uterine contractions. Meanwhile, other factors that influence induction failure are bishop score $<6$ and premature rupture of membranes along with the delivery process.
Relationship of Parity Status with PEB Patient Delivery Method

Based on the results of this study, a p-value of 0.087 was obtained which indicates that there is no significant relationship between the parity status of PEB mothers and the method of delivery they underwent. The prevalence ratio (PR) value obtained is 1.25 , which means that primiparity mothers have a 1.25 times greater risk than multiparity to undergo delivery cesarean.

In research by Andi and Krisna (2018) from the 2017 Indonesian Demographic and Health Survey (IDHS) report, it was also found that there was an insignificant relationship between primiparity and multiparity with cesarean delivery of 0.785 ( $p$ value $>0.05)(12)$.

However, if the bishop score allows for induction, then mothers who give birth to their first child (nulliparity) have a low success rate of labor induction due to the role of parity in the physiology of the reproductive system not working. However, in multiparous women, cervical spasticity and uterine motility have occurred which are still functioning properly. Meanwhile, in grand multiparous mothers, the risk of birth by induction of labor will increase because their reproductive organs are considered to have experienced aging.

\section{Relationship of History of Hypertension with Method of Delivery in PEB Patients Hypertensive states}

Associated with pregnancy, in its various clinical forms, are associated with a greater risk of undergoing caesarean section (CS). The risk of caesarean section in patients with preeclampsia is twofold greater in patients without hypertension. The data from this study are consistent with those found in the literature in several respects, suggesting that patients with a diagnosis of severe preeclampsia are more likely to evolve to caesarean section. The majority of patients who underwent Caesarean section (90.3\%) were patients diagnosed with severe preeclampsia (6). The results of a systematic reviewmeta analysis stated that pregnant women with a history of hypertension had an estimated incidence of 
$41.4 \%(35.5-47.795 \%$ CI $)$ to undergo delivery cesarean 13

Relationship of History of Sectio Caesarea with Method of Delivery in PEB Patients

History of caesarean section is an absolute enough risk factor for cesarean delivery in subsequent pregnancies in preeclamptic patients. A similar relationship was observed in Peruvian women, after verifying that the rate of women with preeclampsia was higher in women who had a cesarean section compared to those who had a vaginal delivery ${ }^{14}$.

History of giving birth by cesarean section is still one of the most influencing factors in subsequent pregnancies regardless of other risks. This is because there are several complications that have a higher risk of arising when vaginal birth after caesarean delivery (VBAC) is performed, some of which are uterine rupture, postpartum bleeding, blood transfusion, hysterectomy due to $\mathrm{PPH}$, use of a ventilator in neonates, seizures in neonates, respiratory distress, even to maternal or neonatal morbidity and mortality (Young, 2019).

Relationship between Bishop Score and PEB Patient Delivery Method

Scott Moses (2019) wrote that the indications for $\mathrm{SC}$ in preeclampsia patients are recurrent seizures, hypertension, poor maternal or fetal condition, and severe preeclampsia with an immature (cervix unfavourable cervix with Bishop Score $<6$ ) at $<30$ weeks' gestation (15). Bishop score relationship with delivery method is to estimate the success of induction. If the Bishop's score is kemungkinan8, the chances of a vaginal delivery are normal and the cervix is said to be good or "ripe" for induction and has a high probability of successful induction and can deliver vaginally. However, if the Bishop's score is 6 , the probability of vaginal delivery is low and the cervix is said to be unfavorable or "immature" for induction and should therefore be considered an alternative cesarean delivery (16). This theory is consistent with the results obtained in this study, where PEB patients with a bishop score $\leq 5$ majority terminated their pregnancies by cesarean section while bishop scores $>5$ were more likely to successfully terminate their pregnancies by vaginal delivery.

The number of observational data on PEB patients based on the bishop score did not meet the total number of samples (210 samples). This is because in the medical record data there are 72 people (34.3\%) whose bishop scores are not explicitly stated. Possibly this is because the 72 people have entered the inpartu phase so that the bishop's score is no longer calculated.

\section{Relationship between IUGR and Method of Delivery in PEB Patients}

Fetal growth retardation is generally caused by placental insufficiency due to poor maternal perfusion, functional placental ablation, or both. If any of these conditions are present, they may be made worse by childbirth. What happens is that the reduced amniotic fluid volume increases the likelihood of cord compression during labour. For this reason, suspected IUGR should undergo "high risk" intrapartum monitoring and delivery is usually cesarean 7 .

The most common cause of IUGR is pregnancyrelated hypertension which occurs in severe preeclampsia, partial HELLP syndrome and total HELLP syndrome. IUGR is also common in earlyonset preeclampsia and severe preeclampsia so that it is more often detected at an early age and results in premature birth if conservative therapy fails.

Macrosomia Relationship with Method of Delivery in PEB Patients Vaginal delivery of macrosomia should pay attention to the presentation and position of the fetus, maternal age, and parity status. Fetal malpresentation in a primiparity mother is an absolute indication for CS. Meanwhile, fetal malpresentation in multiparity mothers may be a relative indication of $\mathrm{SC}$ (17). Macrosomia is associated with the risk of maternal injury, delivery with shoulder dystocia or maternal condition with cephalopelvic disorder, Erb-Duchene palsy, and infant death if vaginal delivery is performed. Therefore, for this reason, macrosomia is one of the indications for cesarean delivery, especially in patients with severe preeclampsia ${ }^{4}$. 
From the results of observations of PEB patients at RSUP Dr. Mohammad Hoesin Palembang January 2018 - December 2019 there were 7 PEB mothers with macrosomic fetuses who underwent cesarean delivery. Two of the seven PEB patients with macrosomia had complications or comorbidities. Characteristics of PEB patients with macrosomia fetuses, one of which has the largest fetal weight of 4250 grams accompanied by other characteristics such as quite extreme age (>35 years), 40 weeks of pregnancy, not yet inpartu, and without complications, so it is very clearly written that macrosomia is an indication absolute value of a cesarean delivery. Other characteristics are PEB patients aged 20 years with a macrosomic fetus $(4000$ grams), 42 weeks post-term pregnancy, multiparity with a history of CS, and the presence of complications such as anhydramnios, so that macrosomia is not the only indication for cesarean delivery.

\section{Relationship between PROM and Method of Delivery in PEB Patients}

Premature rupture of membranes at gestational age $>$ 37 weeks, it is recommended to first be induced with oxytocin. However, if induction fails, cesarean delivery may be considered. In this PROM condition, what is feared is that infection can occur either in the mother (chorioamnionitis) or in the baby (septicemia, pneumonia, or omphalitis). If there are signs of infection, give high doses of antibiotics and labor is terminated. If the pelvic score (bishop score) $<5$, perform cervical ripening, then induction. If that doesn't work, end the labor by cesarean section. However, if the pelvic score (bishop score) is $>5$ successful induction of labor may be higher and vaginal delivery may be considered 3 .

\section{Relationship of Complications or Other Comorbidities with Methods of Delivery of PEB Patients}

In fetal complications in the form of fetal distress or fetal distress, a significant relationship was found at $\mathrm{p}=0.017$ ( $\mathrm{p}$ value $<0.05$ ) with caesarean section delivery in pregnant women with preeclampsia 16.

Case report of the Department of Anesthesiology and Intensive Therapy at Dr. Hospital. Soetomo, Surabaya reported three cases of reference to the condition of the mother pregnant preeclampsia is severe or eclampsia and complications in the form of edema of the lungs (pulmonary edema). From the report the three cases mentioned, everything is done termination of pregnancy emergency section caesarean after doing procedures like beginning to stabilize the condition of the patient 18 .

Of the many variables were tested in test bivariate, there are four variables that have a relationship with the method of delivery on maternal pregnant PEB at Hospital Dr. Mohammad Hoesin Palembang Period 1 January 2018 - 31 December 2019 namely history of sectio caesaria (SC), bishop score, and complications or accompanying conditions. The odds ratio value obtained was 6,951 (2,441 - 19,794 for history of sectio caesaria (SC), 10,299 (5,035 - 21,068) for bishop score, and 3,211 (1,578 - 6,531) for complications or comorbid conditions so that the most dominant risk factors influence the determination of the method. PEB patient delivery is bishop score.

There is a difference between the results of this study and those conducted by Andi and Krisnawati (2018) which states that the most significant and dominant factor has a relationship with the occurrence of cesarean delivery, namely maternal age $>35$ years $(\mathrm{p}=0.000 ; \mathrm{OR}=1.62)$ and macrosomia $(p=0,000 ; O R=1,61)$. The results are showing that extreme old maternal age ( $>35$ years) is a risk factor for the most substantial influence on labor in SC by 1.62 times 12 .

\section{Conclusion}

Based on the research that has been done at RSUP Dr. Mohammad Hoesin Palembang on 210 samples of PEB patients for the period January 2018 - December 2019 , it was found that the factors of gestational age, parity status, history of SC, bishop score, and the presence of complications or comorbid conditions had a significant relationship with $\mathrm{p}$ value $<0.05$. From the multivariate results, it was also found that the bishop score was the most dominant factor in 
determining the method of delivery for PEB patients.

\section{References}

1. ACOG. Clinical Management Guidelines for Obstetrician - Gynecologists. Obstet Gynecol. 2019;133(76):168-86.

2. POGI. PNPK Diagnosis dan Tatalaksana Preeklampsia. 2016;1-48.

3. Prawirohardjo S. Ilmu Kebidanan. Jakarta Yayasan Bina Pustaka Sarwono Prawirohardjo. 2016;

4. Lathifah N, Rahman topan aditya, Safitri Y. INDIKASI RELATIF PADA PERSALINAN DENGAN SECTIO CAESARIA. J Ilmu Kebidanan. 2018;6:87-98.

5. Amorim MMR, Katz L, Barros AS, Almeida TSF, Souza ASR. Maternal outcomes according to mode of delivery in women with severe preeclampsia: a cohort study. 2014;7058:1-7.

6. Linhares JJ, Macêdo NMQ, De Arruda GM alverne, Vasconcelos JLM, Saraiva TDV, Ribeir AF. Fatores associados à via de parto em mulheres com pré- eclâmpsia. Rev Bras Ginecol e Obstet. 2014;36(6):259-63.

7. Cunninghum FGLKJHB etc. Williams Obestetrics, 25th edition. In 2018.

8. Karta Asmana S, Syahredi S, HilbertinaN. Hubungan Usia dan Paritas dengan Kejadian Preeklampsia Berat di Rumah Sakit Achmad Mochtar Bukittinggi Tahun 2012 - 2013. J Kesehat Andalas. 2016;5(3):640-6.

9. Dunn L, Kumar S, Beckmann M. Maternal age is a risk factor for caesarean section following induction of labour. 2017;1-6.

10. Excellence NI for $\mathrm{H}$ and $\mathrm{C}$. Hypertension inpregnancy: diagnosis and management. NICE Guidel [Internet].

2020;(June 2019). Available from:

https://www.nice.org.uk/guidance/ng13

3/informationforpublic

11. English FA, Kenny LC, McCarthy FP. Risk Factors and Effective Management of Preeclampsia. Integr Blood Press Control. 2015;8:7-12.

12. Sulistianingsih AR, Bantas K. PELUANG MENGGUNAKAN METODE SESAR PADA PERSALINAN DI INDONESIA ( ANALISIS DATA SDKI TAHUN 2017). J Kesehat Reproduksi. 2019;9(2):125- 33.

13. Bramham K, Parnell B, Nelson-piercy C. Chronic hypertension and pregnancy outcomes: systematic review and metaanalysis. BMJ Open Respir Res. 2014;2301(April):1-20.

14. Gonzales GF, Tapia vilma L, Fort AL, Betran AP. Pregnancy Outcomes Associated with Cesarean Deliveries in Peruvian Public Health Facilities. Int J Women's Heal Dovepress. 2013;(October)

15. Moses S. Delivery Indications in $\mathrm{PIH}$ [Internet]. Family Practice Notebook. 2019. Available from: https://fpnotebook.com/mobile/cv/ob/pr clmpsdlvryindctns.htm

16. Edwardp C, Witter FR. Preeclampsia, Labor Duration and Mode of Delivery. Int J Gynecol Obstet. 1997;57:39-42.

17. Setiawan AH, Airlangga PS, Rahardjo E. Komplikasi Edema Paru pada Kasus Preeklampsia Berat dan Eklampsia. Vol. 11. 2019. p. 136-44. 